\title{
Burnout Dimensions with Work-Family Conflict among Hotel Employees: Flow Experience as Mediating Role
}

\author{
Mark Kasa ${ }^{1 *}$ and Zaiton Hassan ${ }^{2}$ \\ 1,2 Universiti Malaysia Sarawak, Kota Samarahan, 94300, Sarawak, Malaysia
}

\begin{abstract}
Objective - It is a known fact that hotel employees are constantly working in a demanding work environment. The gruelling demand of the day-to-day operations and stress will eventually lead to the burnout dimensions (exhaustion and disengagement). This may have adverse effects to their relationship with their family members. Interestingly, Malaysian's cultural dimension - collectivism; may explain this in a rather interesting discussion. Previous studies had revealed fascinating findings of a relationship between the burnout dimensions with work-family conflict (WFC) and how flow mediates the relationship between burnout dimensions with WFC

Methodology/Technique - A primary survey of 233 hotel employees in Kuching, Malaysia revealed that indeed there is a correlation between the relationships and that flow mediates the variables.

Findings - The results obtained from this study suggest the importance of hotel organizations in utilizing some proactive actions to promote flow experience among their employees. This article also discloses the practical implications and provides suggestions for future research in the similar field of study.

Novelty - The research provides supported suggestions for proactive action to eliminate burnout at workplace.

Type of Paper: Empirical
\end{abstract}

Keywords: Burnout dimensions; Disengagement; Exhaustion; Flow; Hotel industry; Work-family conflict. JEL Classification: J21, J24, J51.

\section{Introduction}

Depending on their job scope, employees often experience different levels of job-related distress which will ultimately expose them to exhaustion, disengagement, and health-related issues (Schaufelli \& Greenglass, 2001). Consequently, their performance in the workplace will also be affected. Hotel employees often undergo burnout due to excessive work, being underpaid, working through unrealistic working hours, lack of appreciation, and the highly challenging nature of the hotel line (Nelson \& Burke, 2000).

In recent years, studies on employee burnout have been conducted rather extensively and across multiple working disciplines (Chang, Chou, Liou, \& Tu, 2016). Even so, there is a rather limited number of literature in this field of study conducted to investigate the burnout dimensions (disengagement and exhaustion),

\footnotetext{
* Paper Info: Received: December 5, 2016

Accepted: April 24, 2017

* Corresponding author:

E-mail: ekmark@unimas.my

Affiliation: Faculty of Cognitive Sciences and Human Development, Universiti Malaysia Sarawak
} 
particularly focusing on hotel employees in the Eastern region, as noted by Karatepe (2011) and Kasa \& Hassan (2015). As a response to this, this study aims to bridge that gap by providing findings to enhance the necessary knowledge on hotel employee burnout, its dimensions, focusing particularly in the East.

The challenging working conditions in the hotel could be the fitting environment for flow experience to occur, which would then prompt employees to maximize their strength and skills to perform their task in both an enjoyable and motivating manner (Csikszentmihayi, 2003). With such conditions, this current study investigated the potential for flow to mediate the burnout dimensions and WFC.

\section{Literature Review and Hypothesis}

\subsection{Burnout and Its Dimensions}

Maslach, Schaufeli, \& Leiter (2001) defined burnout as a process of depersonalization, reduced personal accomplishment, and exhaustion. This particular viewpoint was later refined by Gorgievski \& Hobfoll (2008) whom modified the term 'burnout' as the end state of a gradual, long term process where resources such as physical, emotional, and cognitive energy are lost. Bakker, Demerouti \& Schaufeli (2005) constructed the framework of burnout as a work-related, stress-reaction that happens to employees regardless of occupation. The negative connotation exists even in an organizational perspective, where it is concluded that employee burnout "increases organizational costs and reduces organizational productivity" (Kasa \& Hassan, 2016, p. 421 ) as it could possibly contribute to undesirable outcomes (Palmer et al., 2004). Even though burnout is often associated with employee's exhaustion and disengagement (Gorgievski \& Hobfoll, 2008; Maslach, Schaufeli, \& Leiter, 2001), this affiliation is not strongly supported in hotel industry, particularly so in the Asian region. Previous studies on burnout had contributed to the extensive body of knowledge on the matter and were researched in different working environments and professions (Kasa \& Hassan, 2015; Francisco et al., 2016).

The term 'exhaustion' refers to a consequence of intensive physical, affective and cognitive strain in a longterm effect of prolonged exposure to the job demands (Demerouti, Mostert, Bakker, 2010). Individuals who experience exhaustion are actually undergoing excessive psychological and emotional demands (Deckard et al., 1994). Meanwhile, disengagement denotes a meaning of an extensive and intensive reaction in terms of an emotional, cognitive, and behavioural rejection of the job (Bakker et al., 2003), a view that acknowledges its link on how disengagement affects employees. Pech \& Slade (2006) whom discovered a correlation between the lack of psychological identification and psychological meaningfulness, explained that disengagement reaches its max when employees have to work under poor leadership and the needed trust between managers and subordinates is low. This particular area of research has been covered by few researchers in rather recent studies (Wollard, 2011; Karatepe, 2013), and each brought new dimensions on the literature. As for this study, one of the objectives is to determine the burnout dimensions as the antecedent to WFC.

\subsection{Work-Family Conflict (WFC)}

Greenhaus \& Beutell (1985) viewed WFC as the incompatibility between the employee's work (workload) and family roles. This incompatibility will consequently lead to conflict as the clashing demands from both roles are often competing with one another in priority. Inevitably, as the demands become too overwhelming for employees, their work performance and well-being will later be affected (Brough et al., 2005). Furthermore, past study also revealed burnout results in WFC (Francisco et al., 2016). Though studies were done to investigate on the effects of burnout, and/or exhaustion, and disengagement in the hotel line (Karatepe, 2013; Kasa \& Hassan, 2015), there was very limited literature that focussed on the burnout dimensions with WFC among hotel employees in Asia. In addition, the matters of disengagement and exhaustion have been observed beforehand though the focus was centred on the account that WFC mediates the relationship between work overload and exhaustion and disengagement (Karatepe, 2013). In conclusion, the availability of studies between the burnout dimensions and WFC in the hotel industry is significantly limited. Based on the limitation 
stated above, the following hypotheses are proposed for this study: (H1) There is a relationship between exhaustion and WFC and (H2) There is a relationship between disengagement and WFC.

\subsection{Flow}

According to Csikszentmihalyi (1990), flow is defined as a state where individuals are engaged in deep concentration whilst doing an activity in a passionate manner. This quality can be a strong aspect in the field of human resource management as flow will increase the employees' overall productivity and thereafter will motivate them to show better work performance, makes them more efficient, and at the same time, increases employees' resiliency at workplace, as noted by Ensenger and Rheinberg (2008). Based on current findings, flow has often been linked to positive improvements among employees. In their personal life, flow assists employees by improving the positive mood they experienced back home by reducing the conflict between work and family (Frone, 2000).

There have been numerous studies on flow, though there is, at present, no known research conducted that utilized flow as the mediator for human resource-related studies among hotel employees in eastern context. As mentioned earlier, working in the hotel environment can be very challenging for employees, as the demanding workload may affect both their professional and personal life. Thus, to fill this specific research gap, the following hypotheses are proposed: (H3) Flow mediates the relationship between exhaustion and WFC and (H4) Flow mediates the relationship between disengagement and WFC.

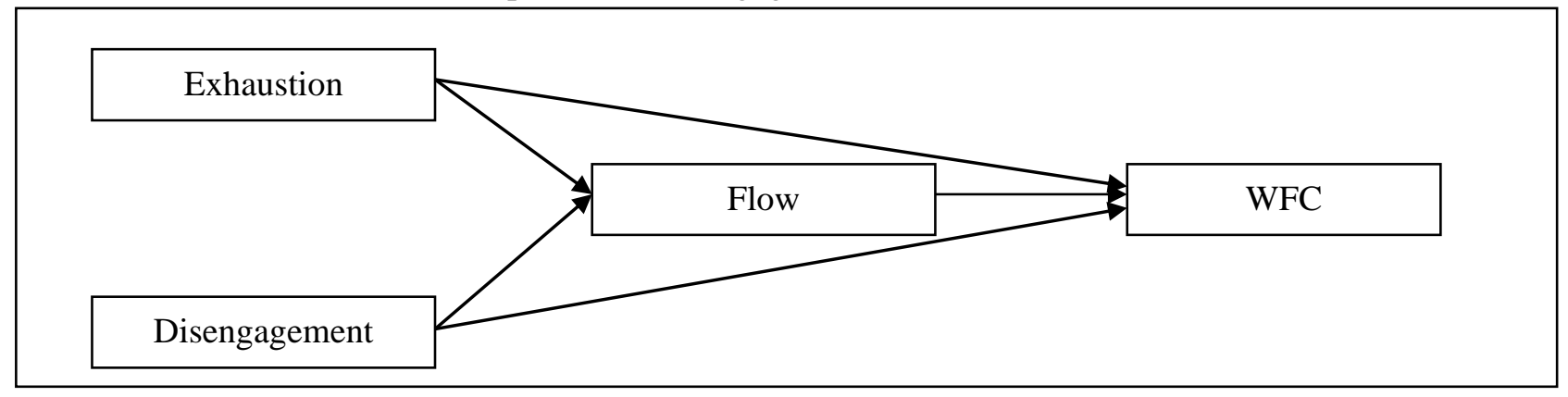

Figure 1: The Research Conceptual Model

\subsection{Underpinning Theory}

This study utilized the Conservation of Resources theory proposed by Hobfoll (1989) as its underpinning theory. This motivational theory posits that individuals constantly aim to "strive to retain, protect, and build resources". Thus, "the potential or actual loss of these valued resources" is considered as a contradictory value. The resources referred by Hobfall (1989) include status, position, loved ones, economic stability, basic beliefs, or self-esteem". However, environmental circumstances are concluded to be the reason that brought the causes to threaten or deplete people's resources. As hotel employees have their own personal and professional wellbeing (resources) that are prone to being threatened by working in the stressful working environment (threats), this theory thus shows an interesting correlation for the basis of this study.

\section{Methodology}

The instruments (self-administered questionnaires) used for this paper were adopted and adapted from past studies and were constructed in both English and Bahasa Melayu. As the research objective was to sample fulltime hotel employees in Kuching, non-probability purposive sampling was deemed to be the most fitting method, hence it was employed for this research. In order to ensure the reliability and validity of the research's instruments and to eliminate any error and ambiguity in the chosen methods, a pilot study was conducted prior to the actual research. It is also important to mention that the data collection process was only commenced upon getting approval from each hotel's management. In the actual study, 300 questionnaires were distributed 
and of which, 233 were returned. The number of sample collected showed an amount higher than 107 respondents, which was calculated using $G^{*}$ Power 3.1.9.2 (with the 2 indicators and output of parameter of actual power at 0.95 ). This study utilized quantitative method involving descriptive statistics and inferential statistic that was based on the use of Scientific Package for Social Sciences (SPSS) version 21. There had been no issues found regarding the validity and reliability discovered in the actual study phase for all constructs, which is proven as follows; (i) the items for each construct exceeded the factor loadings of 0.40 (Hair et al., 1998), (ii) exceeded the acceptable standard of KMO's value of 0.7, and (iii) in terms of Bartlett's test of Sphericity, the value less than .05 indicated that correlation matrix was significantly different from an identity matrix (Hair et al., 1998).

In this study, a total of 41 items were employed in the questionnaire. A total of 16 items, adopted from the Oldenburg Burnout Inventory (OLBI)'s study by Demerouti, Mostert, \& Bakker (2010). The items were constructed based on the score made on a 5-points scale, ranging from (1) "Strongly Disagree" to (5) "Strongly Agree". The OLBI instruments contain two factors - exhaustion and disengagement, which is required for the research's objective. To measure work-family conflict (WFC) in this study, a 5-points scale was used as well, ranging from (1) "Never" to (5) "Very Often" to score the responses. These particular instruments inspired by Bohen \& Viveros-Long (1981)'s theory/method/research, were used to determine the rate/level of respondents' concerns over their work and family roles. High scores of the result reflected a high level of WFC. Thus, the flow was assessed with the work-related flow instrument (WOLF; Bakker, 2008); consisting of 13 items. The reliability $(\alpha)$ value for the burnout, work-family conflict and flow is $0.805,0.839$ and 0.880 respectively.

\section{Results}

\subsection{Respondents' Demographic}

The 233 respondents consisted of 157 females and 76 males. Age-wise, the majority of the respondents are of the age group of 21 to 29 years old $(51.1 \%)$, followed by those who are below 20 years old (24.9\%), 30 to 39 years old (18\%), 40 to 49 years old $(5.6 \%)$, and 50 years old and above $(0.4 \%)$. In terms of their marital status, single respondents made up the largest percentage of $82.4 \%$ while the remaining $17.6 \%$ are married. As for the length of service, a proportion of $60 \%$ of the respondents have been working for less than 1 year, followed by $32 \%$ who have worked for 2 to 6 years, 5\% for 7 to 11 years, and 3\% for 12 to 16 years. The results also indicated the education level of the respondents varied as follow; the largest group were of Bachelor's degree holder (42.9\%), followed by Diploma/STPM/HSE (36.9\%), SPM/MCE (10.7\%), Master's degree $(6.9 \%)$, and at $3 \%$ each for PMR/SRP/LCE and others. When asked about the frequency of the respondents taking their work back home, $36 \%$ responded "Never", followed by $30 \%$ "Sometimes". $21 \%$ "Frequent", and 13\% "Very Frequent".

\subsection{Hypotheses Testing}

This study has four hypotheses as mentioned below:

Hypotheses 1 proposed a relationship between exhaustion and work-family conflict. A Pearson product moment correlation coefficient was computed to assess the relationship between exhaustion and WFC; in which the result revealed that the two variables are significantly related $[r=0.352, n=233, p=.000]$.

Hypotheses 2 suggested that there is a connection between disengagement and WFC. A Pearson product moment correlation coefficient was analyzed and it was revealed that disengagement is indeed related to WFC $[\mathrm{r}=0.176, \mathrm{n}=233, \mathrm{p}=.007]$. 
Table 1: The Hypotheses Testing for Direct Correlation

\begin{tabular}{|c|c|c|c|c|}
\hline & & Exhaustion & Disengagement & $\begin{array}{l}\text { Work-Family } \\
\text { Conflict }\end{array}$ \\
\hline \multirow{2}{*}{ Exhaustion } & Pearson Correlation & 1 & & \\
\hline & Sig. (2-tailed) & & & \\
\hline \multirow{2}{*}{ Disengagement } & Pearson Correlation & $.114 * *$ & 1 & \\
\hline & Sig. (2-tailed) & .082 & & \\
\hline Work-Family Conflict & $\begin{array}{l}\text { Pearson Correlation } \\
\text { Sig. (2-tailed) }\end{array}$ & $\begin{array}{l}352 * * \\
.000\end{array}$ & $\begin{array}{l}.176^{* * *} \\
.007\end{array}$ & 1 \\
\hline
\end{tabular}

**Correlation is significant at the 0.01 level (2-tailed)

In analyzing the significant mediating effect (flow) between the predictors (exhaustion and disengagement) and the outcome (work-family conflict), the Preacher \& Hayes (2004)'s approach of analyses was best to explain the results and thus was utilized in this study. The Preacher and Hayes (2004)'s approach of analyzing the mediator model theory was provided through SPSS macros. This SPSS macros approach facilitates the process of obtaining an estimation of the indirect effect in simple mediation model as well as a bootstrap approach in order to obtain the confidence intervals (Mackinnon et al., 2007). Based on Preacher \& Hayes (2004)'s approach, the significant value should be quantities above zero or of positive value $(>0 /+$ value). Furthermore, it is important that the bootstrap upper and lower bound value be above zero or of positive value (>0/ + value) to be able to determine the significance of indirect effect of the mediator variable.

Hypotheses 3 suggested that flow has a mediating effect between exhaustion and work-family conflict. Based on the regression-based analyses through bootstrapping output, the outcome obtained revealed that the significant indirect effect of flow in correlation between disengagement and WFC is significant at $0.2028^{* *}$ (LLCI .0904, ULCI .3267).

Hypotheses 4 proposed that flow has mediating effect between disengagement and work-family conflict. By adopting Andrew Hayes' matrix output from regression-based approaches, the analyses obtained disclosed the significant indirect effect of flow correlated, between disengagement and WFC conflict, is significant at $0.0858 * *$ (LLCI .0263, ULCI .1671).

The results demonstrated a mediating effect of flow on the correlation between exhaustion and WFC, as well as disengagement and WFC. Thus, it can be concluded that $\mathrm{H} 3$ and $\mathrm{H} 4$ are both supported.

\section{Discussion}

In this study, it was firstly suggested that a relationship between exhaustion and work-family conflict is in fact, existing. As put forward by Demerouti, Mostert \& Bakker (2010), exhaustion is caused by workplace's emotional demands and the feelings of being over-extended. Particularly in the hotel line, the workload can be too exhausting, both physically and emotionally, which drains the employees' energy and affects their state of wellbeing.

The second premise of this study is that there is a correlation between disengagement and work-family conflict, which, based on the results obtained, is supported. To get a better grasp on this assumption, plausible explanation can be referred to Kahn (1990) and Pech \& Slade (2006)'s study; it may as well be that the hotel employees may have little psychological identification and perceived little meaningfulness between their work and themselves. As the majority of the hotel employees were Bachelor degree holders (42.9\%), and there is a possibility they might not see the significance of their degree with their line of work, which in return promotes detachment from their workplace and subsequently causes the feeling of disengagement.

The third research hypothesis argues that flow mediates the relationship between exhaustion and WFC. This premise is also proven to be supported. Even though the majority of the respondents are single (82.4\%), it can be assumed that flow experience does help employees to ward off the negative effects of work exhaustion from affecting their personal life. By being focused on the tasks, they tend to see their work as rewarding and 
beneficial for the long run. This motivates them to complete said task and even have the need to take their work home (as $64 \%$ of the respondents brought their work home). In other words, the benefits that come from flow experience balance out the ill effects of exhaustion from WFC. Unfortunately, this finding could not be supported based on previous studies due the lack of known literature on this research hypothesis.

The final research hypothesis is that flow mediates the relationship between disengagement and WFC, which is supported. Majority of the respondents have been working for less than a year (60\%), indicating that they have yet to be fully acculturated with their organizations' work culture and a strong sense of belonging to their workplace may not be fully present. With flow, that feeling of disengagement is set aside, which in turn, causes the effects of WFC to not be an issue although it exists. This seems to be the reasonable justification to support the hypothesis.

By placing flow as mediator; based on collectivism, work and family boundary are more suitable to be discussed within the Asian context where bringing work home is tolerable. Flow, although is a positive experience, can still create WFC due to inability of the collectivist culture to properly separate work and family domains. This is in agreement with the discovery found in past study in which WFC was shown to be positively correlated to job satisfaction (Hassan, Dollard, \& Winefield, 2010). However, this premise contradicts with findings in the western context. Although employees experience WFC, they are positive about the job because it is an important mean to provide to the well-being of their family.

\section{Conclusion \& Implications}

The burnout dimensions - disengagement and exhaustion - can bring negative effects to the organization, including but not limited to increased organizational costs, a reduction in productivity and the rise of negative impact to employee's family. However, with flow experience as a proactive action done by employers, the dynamic can motivate employee to be more flexible, integrative, and creative (Isen, 2000).

Proactive action is to eliminate, or at the very least, minimize the probability of burnout occurring by providing adequate support to hotel employees' social, mental, and physical wellbeing. The support could be in the form of enhancement of the relationship between employee-supervisor relationship, peer support and care, access to professional counselors, constant and genuine positive affirmation from the management regarding the employees' contribution, and adequate rest for them to spend time with family and friends. If support is continuously delivered, enhancing hotel employees' job performance will be less of a challenge (Brotheridge \& Lee, 2005). Subsequently, the harmonic situation will ultimately improve the hotel's reputation and service. Future qualitative study could also provide other insightful perspectives that will be useful in understanding some of the affecting factor to flow, burnout and WFC.

\section{References}

Bakker, A.B., Demerouti, E., \& Schaufeli, W.B. (2005). Crossover of burnout and work engagement among working couples. Human Relations.

Bakker, A.B., Demerouti, E., Taris, T., Schaufeli, W.B. and Schreurs, P. (2003b), A multi- $\quad$ group analysis of the Job Demands-Resources model in four home care organizations, International Journal of Stress Management, 10(1), 16-38.

Bakker, A. B. (2008). The work-related flow inventory: Construction and initial validation of the WOLF. Journal of Vocational Behaviour, 66, 26-44.

Brough P, O'Driscoll MP, Kalliath TJ. (2005). The ability of "family friendly" organizational resources to predict work family conflict and job and family satisfaction. Stress and Health. 21, 223-234.

Brotheridge, C. \& Lee, R. (2005). Impact of work-family interference on general well-being: A replication and extension. International Journal of Stress Management, 12, 203-221.

Chang, H., Chou, Y., Liou, J., \& Tu, Y. (2016). The effects of perfectionism on innovative behavior and job burnout: Team workplace friendship as a moderator. Personality and Individual Differences, 96, 260-265. http://doi.org/10.1016/j.paid.2016.02.088

Csikszentmihalyi, M., (1990). Flow: The Psychology of optimal experience. New York: Harper and Row. 
Csikszentmihalyi, M. (2003). Good Business, Leadership, flow, and the making of meaning. USA: Penguin Books.

Deckard, G., Meterko, M. \& Field, D. (1994). Physician Burnout: An Examination of Personal, Professional, and Organizational Relationships. Medical Care, 32(7), 745-754.

Demerouti, E., Mostert, K., \& Bakker, A.B. (2010). Burnout and work engagement: A thorough investigation of the independency of both constructs. Journal of Occupational Health Psychology, 15, 209-222.

Engeser, S., \& Rheinberg, F. (2008). Flow, performance and moderators of challenge-skill balance. Motivation and Emotion, 32, 158-172.

Frone, M.R. (2000). Work-family conflict and employee psychiatric disorders: The national comorbidity survey. Journal of Applied Psychology, 85, 888-895.

Francisco, C. De, Arce, C., Vílchez, P., \& Vales, Á. (2016). Antecedents and consequences of burnout in athletes: Perceived stress and depression. International Journal of Clinical and Health Psychology, 16, 239-246.

Greenhaus, J. H., \& Beutell, N.J. (1985). Sources of conflict between work and family roles. Academy of Management Review, 10(1), 76-88.

Gorgievski, M.J., \& Hobfoll, S.E. (2008). Work can burn us out and fire us up. In J.R.B. Halbesleben (ed.) Handbook of stress and burnout in health care (pp 7-22). Hauppage, New York: Nova Publishers.

Hair, J.F.J., Anderson, R.E., Tatham, R.L., Black, W.C., (1998). Multivariate Data Analysis, $5^{\text {th }}$ edition, New Jersey: Prentice Hall, Upper Saddle River.

Hassan, Z., Dollard, F.M., \& Winefield, A.H. (2010). Work-family conflict in East vs. Western Countries. Cross Cultural Management: An International Journal, 17(1), 30-49.

Hobfoll, S. E. (1989). Conservation of resources: A new attempt at conceptualizing stress. American Psychologist, 44, 513-524.

Isen, A. M. (2000). Positive affect and decision making. In M. Lewis and J.M. Haviland-Jones (Eds.), Psychological and biological approaches to emotion (pp. 75-94). Hillsdale, NJ: Erlbaum.

Kahn, W. A. (1990). Psychological Conditions of Personal Engagement and Disengagement at Work. The Academy of Management Journal, 33(4), 692.

Karatepe, O. M. (2011). Customer aggression, emotional exhaustion, and hotel employee outcomes: A study in the United Arab Emirates. Journal of Travel \& Tourism Marketing, 28(3), 279-295.

Karatepe, O. M. (2013). The effects of work overload and work-family conflict on job embeddedness and job performance: The mediation of emotional exhaustion. International Journal of Contemporary Hospitality Management, 25(4), 614-634.

Kasa, M., \& Hassan, Z. (2015). The Role of Flow between Burnout and Organizational Citizenship Behavior (OCB) among Hotel Employees in Malaysia. Procedia - Social and Behavioral Sciences, 211, 199-206. http://doi.org/10.1016/j.sbspro.2015.11.084

Kasa, M., \& Hassan, Z. (2016). Burnout and Flow with Moderating Effect of Individualism / Collectivism. A Study in Malaysian Hotel Industry. Procedia - Social and Behavioral Sciences, 219(May), 416-423. http://doi.org/10.1016/j.sbspro.2016.05.063

Maslach, C., Schaufeli, W., \& Leiter, M. P. (2001). Job burnout. Annual Review of Psychology, 52, 397-422.

MacKinnon, D.P., Fairchild, A.J., \& Fritz, M.S. (2007). Mediation analysis. Annual Review of Psychology, 58, 593-614.

Nelson, D. L. and Burke, R. J., 2000. "Women Executives: Health, Stress and Success. Academy of Management Executive, 14, 107-21.

Palmer, S, Cary, C., \& Kate, T. (2004). "A model of work stress to underpin the Health \& Safety Executive advice for tackling work-related stress and stress risk assessment." Counselling at Work Journal, Winter, 2004. Center for Stress Management, London.

Pech, R., \& Slade, B. (2006). Employee disengagement: is there evidence of a growing problem? Handbook of Business Strategy, 7(1), 21-25.

Preacher, K, J., \& Hayes, A. F., (2004) SPSS and SAS procedures for estimating indirect effects in simple mediation models, Behavior Research Methods, Instruments, \& Computers, 36(4), 717-731

Schaufeli, W. B. \& Greenglass, E. R. (2001). Introduction on a special issue on burnout and health. Psychology \& Health, $16,501-510$.

Wollard, K. K. (2011). Quiet Desperation. Advances in Developing Human Resources, 13(4), 526-537. http://doi.org/10.1177/1523422311430942 